\title{
Male sterility and gametoclonal variations from gynogenically derived polyploids of tef (Eragrostis tef), zucc. Trotter
}

\author{
Likyelesh Gugsa $^{1,2 \star}$ and Horst Loerz ${ }^{2}$ \\ ${ }^{1}$ Ethiopian Institute of Agricultural Research (EIAR), P. O. Box 2003, Holetta, Ethiopia. \\ ${ }^{2}$ Biocentre Klein Flottbek and Botanical Garden University of Hamburg Ohnhorststr. 1822609 Hamburg, Germany.
}

Accepted 19 December, 2012

\begin{abstract}
The production of plants from the gynogenic culture of tef (Eragrostis tef) was reported from in vitro gynogenesis of unpollinated flower explant of cultivar 'DZ-01-196'. Out of the 159 regenerated R0 lines, 151 tetraploids, 5 di-haploids, 2 aneuploids and 1 octoploid plant were obtained which showed gametoclonal variation in various traits including male sterility. Panicle bending, accessory floret development and larger seed size were among the unique traits obtained. Analysis of variance revealed significant differences for all morphological traits studied in the R0 generations. Tetraploid R0s showed superiority over the control for plant height, flag leaf length and number of florets per spikelet. Male sterility traits were recorded among the tetraploid RO lines mainly due to failure of pollen formation. Though two complete and four partial male sterile lines were obtained in the Ro generation, this trait was not exhibited in those plants raised from the partially male sterile lines. Male sterility and the various gametoclonal variations obtained from this study will facilitate the hybridization and crop improvement program of tef.
\end{abstract}

Key words: Eragrostis tef, gametoclonal variations, gynogenesis, male sterility, regenerated lines, ployploids.

\section{INTRODUCTION}

Tef (Eragrostis tef) is indigenous and widely cultivated staple food crop of Ethiopia. Its wide agronomic versatility, adoptability, relative resistance to diseases and insect pests and economic and nutritious value of 'injera' (thin, flat, pancake-like bread, made from fermented dough of tef) rank it first among other cereals such as wheat, maize and sorghum. However, the improvement of the crop lagged behind that of many

\footnotetext{
*Corresponding author. E-mail: lgugsa@yahoo.com, likyeleshgugsa@uni-hohenheim.de. Tel: +4917699550770.
}

Abbreviations: DHs, Doubled haploids; R0, regeneration zero (the first regenerants); R1, plants derived from R0; R2 and R3, successive generations of R1; 2,4-D, 2,4-dichlorophenoxyacetic acid. other cereals. Lodging is the main bottle neck problem for its low productivity and causes 17 to $25 \%$ yield reduction (Ketema, 1983). To prevent lodging, farmers often used unimproved cultivars with low application of Nitrogen fertilizer; as a result the national average production is below 1.1 ton per hectare (Central Statistics Authority, 2008). Introgression of agronomically desirable traits especially dwarfness from close relatives, to attain lodging resistant varieties through conventional technique did not solve the problem. This is mainly due to the very tedious and painstaking crossing technique of tef, attributed to its pollination habit. Under Ethiopian climatic condition, tef flowers open and pollinate only between 6:45 and 7:45 a.m (Berhe, 1976). Besides, the small size of the flowers and its autogamous nature made microscopic emasculation and cross pollination an obligatory, which requires very experienced personnel since the floret organs especially pistils easily damaged 
Afr. J. Plant Sci.

during surgical emasculation and pollination. Male sterile trait in tef therefore would facilitate crossing and the improvement of the crop as it has improved the breeding programs of many crops such as maize, sunflower and rape seed. However, this trait had never been found either from the rich diversified germplasm collections (Ketema, 1983) of tef or from any mutation or biotechnological tools. Recently, attempts have been made to improve many crops utilizing non-conventional approaches such as in vitro culture techniques and molecular marker analysis. In vitro production of doubled haploids (DHs) is one of the non-conventional techniques commonly employed in many cereal crops such as barley, rice, maize and wheat. The haploid cells regenerated in vitro are subjected to chromosome doubling either spontaneously or mainly through colchicines treatments to produce double haploids (DHs). The DHs development in many plant breeding programs has reduced the time and population size required for the production of pure lines compared to the conventional selfing or back crossing. In many species where DH lines are produced with high efficiency, such as barley (Kumlehn et al., 2006) and rape seed (Bhowmik et al., 2011) the system is now widely applied in breeding and many areas of research, including molecular mapping, quantitative trait loci (QTL) analysis, gene tagging, in vitro mutagenesis and selection or gene transformation (Khush and Virmani, 1996). In majority of the cases haploid and DHs are derived either through androgenesis or wide hybridization.

Alternatively, gynogenesis (regeneration of plants from the female organs) despite the limited explants compared to microspores is another approach to produce haploids where androgenesis is either not applicable or not successful. However, there are limited reports on gynogenesis and gynogenic derived haploids. Gugsa and coworkers (Gugsa et al., 2006) were the first to standardize a gynogenesis technique for the production of di-haploids and various ploidy levels in tef. The highly successful regeneration system exhibited gametoclonal variations. Gametoclonal variation can be considered as an additional option to generate genetic variability in coadopted useful cultivars. Useful traits such as increased tolerance to physiological stresses, pests and diseases have been recovered from somaclones and gametoclones. Picard and Buyer (1977) reported many wheat androgenic $\mathrm{DH}$ gametoclonal mutant lines resistant to powdery mildew and Septoria sp., producing high grain yields. So far tef did not benefit from mutation breeding and no report on gametoclonal variation for important traits such as male sterility. The gynogenically obtained 159 R0 lines derived from the previous study (Gugsa et al., 2006) were analysed for the gametoclonal variation especially male sterility. In this paper the gametoclonal variation for some morphological traits and male sterility mutants of $\mathrm{R} 0$ and $\mathrm{R} 1$ regenerants with various ploidy levels is reported.

\section{MATERIALS AND METHODS}

\section{Plant materials}

Gynogenically obtained tef (Ergarostis tef) regenerated lines obtained from the protocol described by Gugsa et al. (2006) were used for the present study. Immature panicle of cv. 'DZ-01-196' $(2 n=4 x=40)$ were harvested at 14 to $17 \mathrm{~cm}$ of emergence and central segments pretreated at $4^{\circ} \mathrm{C}$ for $36 \mathrm{~h}$ and were cultured on MS (Murashige and Skoog, 1962) medium supplemented with 18 $\mu \mathrm{M} 2$, 4-dichlorophenoxyacetic acid (2,4-D). One hundred and fiftynine (159) first regenerated lines (R0s) were subjected to flow cytometry analysis using the protocol described by the same authors and 151 tetraploid, 5 haploid, 2 triploids and 1 octoploid obtained were used for this study. R0s were planted in pots in the green house at $16: 8 \mathrm{~h}$ photoperiod at $26 \pm 2^{\circ} \mathrm{C}$ in Hamburg, Germany. Plants were fertilized using commercial fertilizer at the rate of $12 \mathrm{~g} /$ pot and N.P.K: 15:8:15 applied once, after three weeks of potting. Seeds were harvested only from the main tillers of R0s. Fifty (50) samples were selected based on observations for traits such as polyploidy level and high yielding components such as panicle length, plant height, number of florets per spikelet, number of spikelets per panicle, grain yield/main panicle and fertility status. Five seeds from these R0s were planted in pots with three replications (each pot considered as a replication) to generate $\mathrm{R} 1 \mathrm{~s}$. R1 plants were grown at Holetta, Agricultural research Center (HARC), Ethiopia. Plants from seeds lot of the donor parent, cv 'DZ01-196' were used as the control.

\section{Morphological data collection}

Data were collected only from main tiller of each plants and the control. Means of the different polyploidy variants; five di-haploids (2n), $15(10 \%$ of the total) tetraploid $(4 n)$, one octoploid $(8 n)$ and the control $(4 n)$ plants were calculated. $R 1$ data was collected from 3tagged samples from each pot. Observation were recorded for plant height, panicle length, culm thickness, number of florets per spikelet, number of spikelets per panicle, panicle form, main panicle weight, 1000 seed weight and grain yield/main panicle. Statistical analysis was carried out using T-test.

\section{Fertility investigation}

To evaluate individual plant fertility; normal or variant panicle, spikelet and floret development, and seed setting per spikelets were examined visually. Panicles of 1-2 tillers per plants were covered using paper bag to avoid any cross pollination that might occur. At seed setting stage, number of seeds set per spikelets was counted among the Ro regenerants and fertility status of the genotypes was estimated following Elkonin et al. (1994) method. Male sterile plants were recognized with the production of anthers without pollen grains dehisced on fresh receptive stigmas. Mutants having zero to one seeds per spikelet were considered as complete sterile, one to two seeds per spikelet as partial sterile and more than 6 seeds per spikelet as fertile having more than $50 \%$ seed set.

\section{Microscopic investigation of reproductive organs}

A sample of about 50 anthers per plant was collected from intermediate part of the panicles of di-haploids, octoploids and tetraploids plants including the control and investigated under binocular microscope. The normal development of floret organs such as anther and pollen grains structure and size, presence or absence of pollen grains in the anthers, number of pollen grains in each anther and their pollen viability were tested using $25 \mathrm{mM}$ $\mathrm{CaCl}_{2}-0.3 \mathrm{M}$ maltose solution. 
The viability of the pollen grains were also examined whether it contains starch granules or not, deformed shape and smaller size, and darker pollen. Anthers and pollen grains size was measured microscopically at 200X and 400X magnifications, respectively.

Adoptability and trait performance of the complete male sterile, partially fertile and the octoploid line in the successive generations were studied using flow cytometry analysis, fertility and gametoclonal variations. For this 5 seeds of selected $27 \mathrm{R} 0 \mathrm{~s}$ including completely sterile, partial and fully fertile and the octoploid plants were planted on $17.5 \times 19 \mathrm{~cm}$ nursery pots filled with 2:2:1 black: red: and sand soil at the lath house of HARC at the main growing season.

\section{RESULTS}

The majority of the gynogenically regenerated plants $(\mathrm{R} 0)$ grown were normal, vigorous, and without any albino type except some abnormalities like deformed florets and incomplete panicle emergence. Similarly most of the R1 plants grown at HARC also showed normal growth without albinism. However, gametoclonal variations for different morphological traits among the various polyploids (di-haploids, tetraploids and octoploid compared to the control are depicted in Figure 1.

Structurally, di-haploids have narrow leaf while tetraploids and octoploid borne wide leaf, the latter comparatively larger in plant and leaf size (Figure 1a and $\mathrm{b}$, center). Distinctive variation in panicle forms (Figure 1c-e) where the donor parent with fairly loose panicle form (Figure 1C) produced variant forms, from compact to very loose (Figure 1d) and additional unique panicle bending trait (Figure 1e) from the regenerated $\mathrm{R} 0$ lines. Plant height (Figure 1f) and fertility (Fig 1g (di-haploid sterile) and (tetraploid fertile) were all derived from the culture of a single cv 'DZ-0-196' through gametoclonal variations. Thirteen (13) of the $159 \mathrm{R} 0$ lines exhibited panicle bending at varying angle $\left(45\right.$ to $\left.90^{\circ} \mathrm{C}\right)$ down ward to the culm. The higher accessory floret development per spikelet (Figure 1j-m) was one of the gametoclonal variation observed from this cultivar which typically carries no more than 10 florets per spikelet. This trait is one of the important yield components and two of the 151 tetraploid $\mathrm{R} 0$ lines possessed 19 florets per spikelet in in vivo conditions (Fig 1I) and 10 to 14 seeds were obtained from each spikelet compared 5 to 7 of the control. Though high number of floret was also obtained from the di-haploids (Figure 1j) but no seed setting was observed in the 4 out of 5 di-haploids. Only one di-haploid plant setted seed after the main panicle branch unexpectedly died and new relatively productive branches emerged and produced 1 to 2 smaller seeds per spikeletes. The seed size of this di-haploid plant was $0.6 \mathrm{~mm}$ compared to the $1.6 \mathrm{~mm}$ of the control and 2.1 of the octoploid line (Gugsa et al., 2006).

The extent of variability for some morphological traits within the tetraploid regenerants of R1 generation was greater than the control (Table 1). For instance, plant height range was 74 to $227 \mathrm{~cm}$ among regenerants while only 165 to 218 for the control. Panicles length ranged between 20 to $79 \mathrm{~cm}$, flag leaf length from 24 to $80 \mathrm{~cm}$, number of leaves 4 to 13 , number of nodes, 4 to 8 , culm thickness, 0.16 to $0.48 \mathrm{~cm}$ while the variation among the tested control plants was not high (Table 1). For instance, for number of nodes 6 to 7 , for number of leaves 6 to 8 and for culm thickness was 0.25 to $0.30 \mathrm{~cm}$.

The gametoclonal variations for the yield limiting components such as number of spikelets/panicle, floret number per spikelet, panicle weight and grain yield per main panicle was high compared to the control plants. As shown in Table 1, number of floret per spikelet was 4 to 19 and 7 to 10.0 ; for panicle weight 0.35 to $2.35 \mathrm{~g}$ and 0.7 to $0.8 \mathrm{~g}$; for yield per main panicle, 0.25 to $2.15 \mathrm{~g}$ and 0.4 to $0.6 \mathrm{~g}$ among the $\mathrm{R} 0$ tetraploid regenerants and the control plants in that order. With regard to population mean the R0 lines recorded superiority over control plants for most morphological data collected such as panicle length, number of leaves, number of florets per spikelet and culm thickness.

Analysis of variance revealed significant differences for all morphological traits studied in the Ro generations which include various polyploids. Tetraploid R0s showed superiority over control for all traits measured (Table 2). Mean variation for plant height ranged from 173 to 241 $\mathrm{cm}$ and panicle length $34.6 \mathrm{~cm}$ in di-haploids and $64.2 \mathrm{~cm}$ in tetraploids. Number of spikelets per panicle was maximum 421.8 in tetraploid and minimum 219.0 in dihaploids while octoploids were at par with the control. Number of florets per spikelet was observed more in all polyploids than that of the control. Tetraploids possessed maximum mean of 12.5 florets per spikelet while the control only 9.5 . Panicles borne on octoploid were slightly and significantly heavier $(1.55 \mathrm{~g})$ than tetrapaloids $(1.46$ g) while those borne on di-haploids were lighter in weight $(0.30 \mathrm{~g})$. In the control they were just half of the tetraploids. Tetraploids with heavier panicle gave higher yield of $1.29 \mathrm{~g}$ while di-haploids lighter panicle produced low yield $(0.20 \mathrm{~g})$ compared to the control $(0.47 \mathrm{~g})$. In octoploid, test 1000 grain weight was maximum $(0.530 \mathrm{~g})$ followed by tetraploids $(0.495 \mathrm{~g})$ and control $(0.364 \mathrm{~g})$ while di-haploids recorded the least $(0.27 \mathrm{~g})$. There was no segregation for phenotypic characters (panicle form, lemma color and seed size in the progeny of the octoploid grown for three generation (R1, R2 and R3) but all plants derived from the di-haploid seeds were converted to fertile tetraploids with smaller seed size and whitish embryo color while the octoploid plants still had larger seed sizes with relatively darker embryos than the control and generally seed color was pale white. Moreover, all plants regenerated from the octoploid plant were partially fertile, $40 \%$ compared to $80 \%$ of the control (Table 3)

\section{Microscopic examination}

Tef flowers are hermaphrodite bearing a pistil with three stamens (Figure 2a). In pistil, ovary has two styles each 


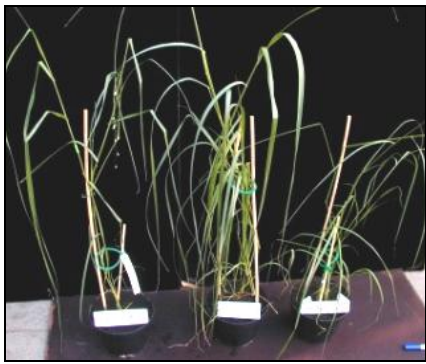

a

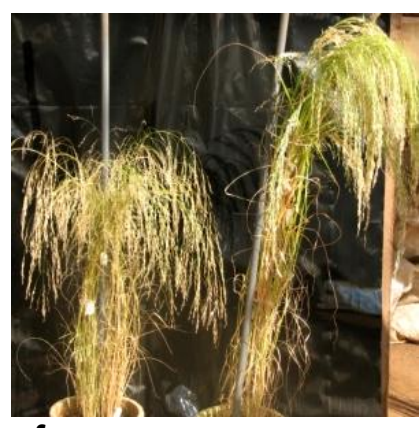

$\mathbf{f}$

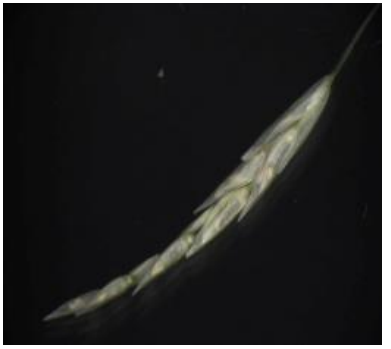

j

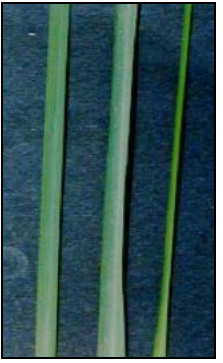

b

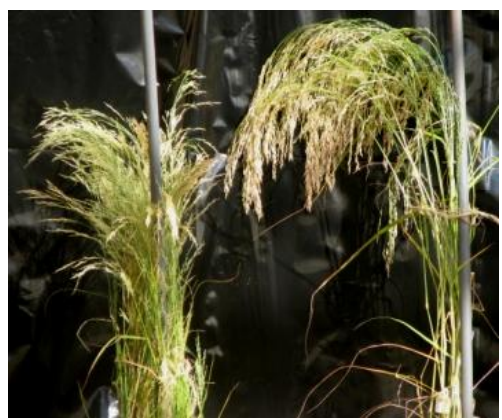

g

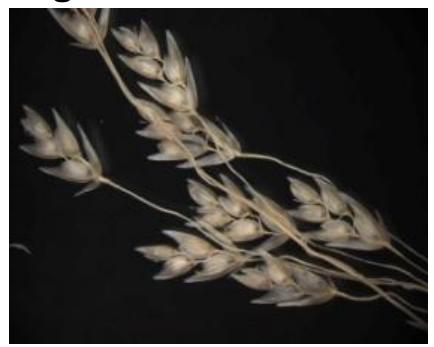

k

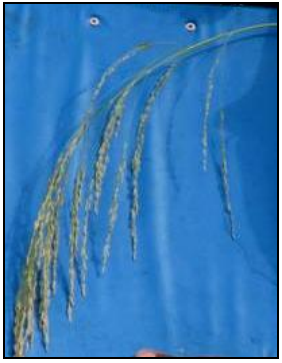

C d

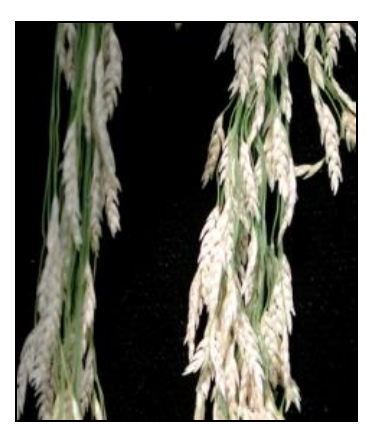

h

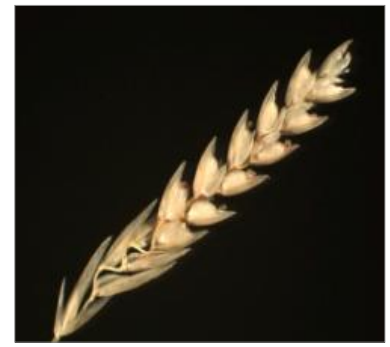

I

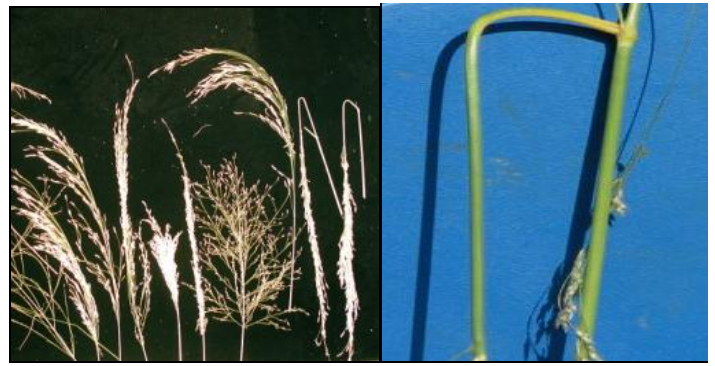

e
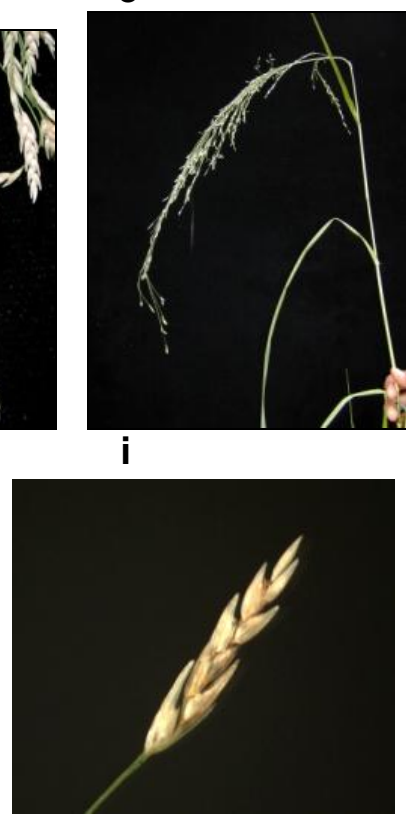

m

Figure 1. Morphological characterization of gametoclonal variant tef plants derived from gynogenic culture of cv. 'DZ-01-196' a) plants from the three polyploidies a) tetraploid (left), octoploid (center) and di-haploid (right) and their leaf widths from the freshly cut samples (b); panicle form variations; fairly loose (control c) compared to various forms derived: compact to very loose (d) and unique panicle bending trait (e), plant height and panicle form variations of two tetraploid lines (f), fertility variation; di-haploid plant (g left, no set seed in all spikelets compared to the fertile tetraploid plant (right), vigorous panicle size with high seed setting variation of two tetrploid line $(\mathbf{h})$ compared to inferior spikelet formation (i), variations in number of floret/spikelets and seed setting; di-haploid spikelet with eleven florets but no seed set (j); tetaploid fertile lines with 4-5 (k) and 18 florets/ spikelet (I) compared to the control plant with 9 florets/ per spikelets (m).

Table 1. Range of variation for different morphological traits in regenerated tetraploid $R 0$ plants derived from in vitro culture of un-pollinated flower explant compared to the control cv. 'DZ-01-196'. For all measurements only panicles from main tillers were used.

\begin{tabular}{lcccccc}
\hline \multirow{2}{*}{ Trait } & \multicolumn{2}{c}{ Regenerated R0 plants } & \multicolumn{3}{c}{ DZ-01-196 (Control) } \\
& \multicolumn{2}{c}{ 2n=4x } & & & 2n=4x & Mean \\
\cline { 2 - 7 } & Minimum & Maximum & Mean & Minimum & Maximum & Mexime \\
\hline Plant ht (cm) & 74 & 227 & 105.5 & 165 & 218 & 191.5 \\
Panicle length (cm) & 20 & 79 & 59.5 & 30 & 56 & 43 \\
Flag leaf length (cm) & 24 & 80 & 52 & 48 & 62 & 55 \\
No. of leaves & 4 & 13 & 8.5 & 5 & 6 & 5.5 \\
No of nodes & 4 & 8 & 6 & 6 & 7 & 6.5 \\
Culm thickness (cm) & 0.16 & 0.48 & 0.32 & 0.25 & 0.3 & 0.275 \\
Panicle wt (g) & 0.35 & 2.35 & 1.35 & 0.7 & 0.8 & 0.75 \\
Number of floret/spikelet & 4 & 19 & 11.5 & 7 & 10 & 8.5 \\
Grain yield per panicle (g) & 0.25 & 2.15 & 1.25 & 0.4 & 0.6 & 0.5 \\
\hline
\end{tabular}


Table 2. Comparison of gynogenically derived tef plants of different ploidy levels compared to wild-type plants regarding agronomically relevant morphological traits. For all measurements only panicles from main tillers were used.

\begin{tabular}{|c|c|c|c|c|c|c|c|}
\hline Polyploids & $\begin{array}{l}\text { Plant height } \\
\text { (cm) }\end{array}$ & $\begin{array}{c}\text { Panicle } \\
\text { length }(\mathrm{cm})\end{array}$ & $\begin{array}{l}\text { No. of spikelets/main } \\
\text { panicle }\end{array}$ & $\begin{array}{c}\text { No of } \\
\text { florets/spikelets }\end{array}$ & $\begin{array}{c}\text { Panicle weight } \\
\text { (g) }\end{array}$ & $\begin{array}{l}\text { Grain yield/ } \\
\text { Panicle (g) }\end{array}$ & $\begin{array}{l}1000 \text { seed } \\
\text { weight }(\mathrm{g})\end{array}$ \\
\hline $1 n=2 x$ & $173.1 \pm 1.3^{\mathrm{c}}$ & $34.6 \pm 0.1^{\mathrm{c}}$ & $219.0 \pm 3.2^{c}$ & $9.0 \pm 0.3^{b}$ & $0.30 \pm 0.2^{d}$ & $0.2 \pm 1.2^{d}$ & $0.27 \pm 0.2^{c}$ \\
\hline $2 n=4 x^{*}$ & $241.0 \pm 2.2^{\mathrm{a}}$ & $64.2 \pm 0.1^{a}$ & $421.8 \pm 2.1^{\mathrm{a}}$ & $12.5 \pm 0.2^{a}$ & $1.48 \pm 0.2^{b}$ & $1.29 \pm 0.7^{\mathrm{a}}$ & $0.495 \pm 0.5^{b}$ \\
\hline $2 n=8 x$ & $166.4 \pm 2.0^{d}$ & $47.6 \pm 0.5^{b}$ & $298.5 \pm 1.7^{b}$ & $10.2 \pm 0.1^{\mathrm{ab}}$ & $1.55 \pm 0.2^{\mathrm{a}}$ & $0.91 \pm 1.2^{b}$ & $0.53 \pm 1.7^{\mathrm{a}}$ \\
\hline control (4n) & $199.4 \pm 1.0^{b}$ & $59.8 \pm 0.3^{a}$ & $297.8 \pm 1.3^{\mathrm{b}}$ & $9.5 \pm 1.5^{b}$ & $0.78 \pm 0.2^{c}$ & $0.47 \pm 0.2^{c}$ & $0.36 \pm 1.1^{c}$ \\
\hline
\end{tabular}

*Only the $10 \%$ highest yielding regenerated tetraploids were analyzed. Values followed by the same letter do not differ significantly from each other ( $P<0.01)$ as calculated by T-test.

Table 3. Sterility percentage and variation in anther and pollen grains size of different polyploids.

\begin{tabular}{|c|c|c|c|c|c|c|}
\hline \multirow{2}{*}{ Polyploids } & \multirow{2}{*}{$\begin{array}{c}\text { No of florets } \\
\text { examined }\end{array}$} & \multirow{2}{*}{$\begin{array}{l}\text { Fertile } \\
\text { florets }\end{array}$} & \multirow{2}{*}{$\begin{array}{l}\text { Sterile } \\
\text { florets }\end{array}$} & \multirow{2}{*}{$\begin{array}{c}\% \text { of } \\
\text { sterility }\end{array}$} & \multicolumn{2}{|c|}{ Size } \\
\hline & & & & & Anther $(200 X) \mu \mathrm{m}$ & Pollen $(400 \mathrm{X}) \mu \mathrm{m}$ \\
\hline Tetraploid (4x), sterile & 50 & 4 & 46 & 92 & $73-80$ & $11-13$ \\
\hline Tetraploid (4x), fertile & 48 & 42 & 6 & 12.5 & $70-86$ & $11-13$ \\
\hline Octoploid (8x) & 42 & 17 & 25 & 60 & $100-105$ & $11-18$ \\
\hline Di-haploid (2x) & 50 & 1 & 49 & 98 & $55-80$ & $9-10$ \\
\hline Control (4x) & 50 & 40 & 10 & 20 & $70-87$ & $11-13$ \\
\hline
\end{tabular}

ending in a plumose (feathery) whitish stigma (Figure 2a). In the cv. 'DZ-01-196' used in the study, sometimes twin and rarely tripled pistils with two-three styles were observed (data not shown). None of this character was observed in the $\mathrm{R} 0$ lines. The size of the reproductive organs of the di-haploid plants was smaller compared to the octoploid and the controls (Figure $2 \mathrm{~b}$ and $\mathrm{c}$ ). Normally anthers of cv. 'DZ-01-196' are light green during early stage and deep red at maturity (Figure 2a) and are two celled, opening lengthwise containing 50 to 100 pollen grains (Figure 2d). Pollen grains from fertile anthers were large and full of starch granules showing more than $80 \%$ viability (Figure $2 \mathrm{e}$ ) and fertility in most tetraploid lines and the control plants (Table 3). The few dead pollens (Figure 2e, black and small (arrows) found in fertile anthers were none viable.

The microscopic examination of the R0 mutants revealed normal as well as variant form of anther structure with varying size and color depending on its ploidy level and fertility status. Measurements of the morphological variations in anther and pollen size of different polyploids are shown in Table 3. Various types of fertility were observed among the 40 to 50 samples taken from each ploidy levels and male sterility is one of the characters observed mainly in the di-haploids but also in few tetraploid mutants. Male sterility recorded in the tetraploid mutants and di-haploids was nearly complete sterility (92 to $98 \%$ ) and the octoploid plant $(60 \%)$ showing partial fertility compared to the control which showed only $20 \%$ (Table 3). Anther and pollen grains were larger in size in octoploid (100 to 105 and 11-18 $\mu \mathrm{m}$, respectively) and smaller (55 to 80 and 9 to 10 $\mu \mathrm{m}$ ) in haploids (Table 3 ) while in tetraploids and control size was almost equal. The octoploid anthers and pollen grains were approximately 2.0 and 0.8 times larger than the di-haploids and tetraploids, respectively (Table 3 ).

In general, five variants of male sterility were observed among the male sterile mutants and the di-haploids (Table 4). i) Normal growth of anthers in size but whitish in color and without formation 
Table 4. Male sterility variations observed in gynogenic derived R0 lines (Sample size 50 anthers.

\begin{tabular}{cll}
\hline S/N & Variation & Observed mainly on \\
\hline 1 & Normal growth of anthers in size and whitish color but devoid of pollen grains (sterile) & Tetraploid/octoploid \\
2 & Production of normal colored and sized but shriveled anthers with no or few pollen grain formation & Tetraploid/octoploid \\
3 & Formation of shriveled anthers with ample non-functional (deformed) pollen grains in the anthers & di-haploids \\
4 & Normal anthers producing normal sized but underdeveloped pollen grains; which failed to & Tetraploids \\
& germinate on the receptive stigmas after dehiscent (no starch granules in the pollen) & \\
5 & Herkogamous condition, (physical barrier) between stigma and filament & octoploids \\
\hline
\end{tabular}

of pollen grains (Figure 2c) instead of deep red color anthers (Figure 2a). This phenomenon occurs mainly in octoploid and sterile mutant plants. ii) Production of normal colored and sized but shriveled anthers with no or few pollen grain formation (Figure $2 \mathrm{~g}$ ). This phenomenon was also observed in octoploid and sterile mutant plant. iii) Formation of shriveled anthers with non-functional (deformed) pollen grains in the anthers (Figure 2f). This was the case for the $98 \%$ of di-haploids male sterile plants. iv) Normal anthers producing normal sized but underdeveloped pollen grains; which failed to germinate on the receptive stigmas after dehiscent (Figure $2 \mathrm{~h}$ ). This was observed in the tetraploid sterile mutants. These anthers were bearing normal pollen grains but empty inside. This means the pollen grains did not undergo the normal microspore cell division to produce fertile pollen grains, with the germ and vegetative cells normally indicated by the presence of many starch granules. iv) Herkogamy: it's not exactly male sterility but mutant plants failed to set seed due to physical barrier between stigma and anthers (Figure 2c). The latter variant was observed in very few florets of the octoploid plants.

All those florets with complete and partial male sterility had normally grown pistils with widely emerged receptive feathery stigmas but pistils shriveled and dried without being self pollinated.

\section{DISCUSSION}

Tef is normally allo-tetraploid and there has been no report on variant ploidy levels (Ayele et al., 1996). Existence of various polyploids in the gynogenically derived tef lines such as octoploids without addition of any chromosome duplidizing agents like colchicines and oryzalin could be due to the gametoclonal variation (derived from gametic cells) occurred spontaneously in vitro and in vivo. Somaclonal variation (from somatic cells/tissues) and gametoclonal variations in cultured tissues is a common phenomenon in many crop species (Huang, 1996). It has been reported that ploidy variations were also generated in tissue cultures of many plant species such as rice (Kanda et al., 1988), sugar beet (Jazdzewska et al., 2000) and water yam (lijima et al., 2010).
Successive cycles of culture and lengthening of the culture phase reported to result in increase in the amount of gametoclonal variation (Hoffmann et al., 1982). However, this could not be the case in the gynogenic tef regenerants since the culture period was very short, 15 to 20 days in induction medium and only 4 to 8 weeks in the regeneration medium (Gugsa et al., 2006). Plant regeneration from lengthy callus culture in vitro also reported as main source of somaclonal variations (Evans and Sharp, 1985; Bairu et al., 2011). However, the absence of callus phase in the gynogenically produced lines of tef, and could be one reason for the gametophytically induced mutation rather than somatic variation. Besides, the spontaneous seed production of the di-haploid tef plant and the achievement of octoplod plant may explain partially the presence of gametoclonal variation in vitro and in vivo. In barley anther and microspore culture more than $80 \%$ of the regenerated plants were spontaneously doubled (Kahrizi and Mohammadi, 2009; Hoekstra et al., 1993). This is in agreement with the present study that $94 \%$ of the regenerated lines were tetraploid although the gametic explants sources for the two plants were different. According to the study of Singh (1986) aneuploids occur spontaneously and may be produced in high frequencies from autotetraploid and tetrasomic plants. Since there was no apparent ploidy report in tef (Ayele et al., 1996), the occurrence of various ploidy levels derived from the gynogenic regenerants of tetraploid parent were likely derived due to the spontaneous doubling in vitro from the allo-tetraploid tef origin. There was no segregation in the octoploid progenies of R1-R3 generations for many economically important traits such as plant height, panicle length, culm thickness, leave and node numbers, seed size, heading and maturity dates (data not shown). The uniformity of these progenies tested may indicate that the octoploid plant was derived only by spontaneous doubling of the haploid gametes in vitro instead of deriving from any somatic tissues of the female organs such as ovary/ovule wall or any other part of the floret organs. Further study on the zygosity of the tetraploid tef lines using modern molecular technique such as simple sequence repeat (SSR) (Malik et al., 2011) could reveal whether spontaneous chromosome doubling and production of homozygous lines were achieved through 


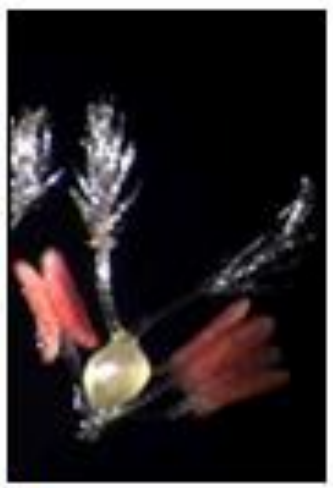

a.

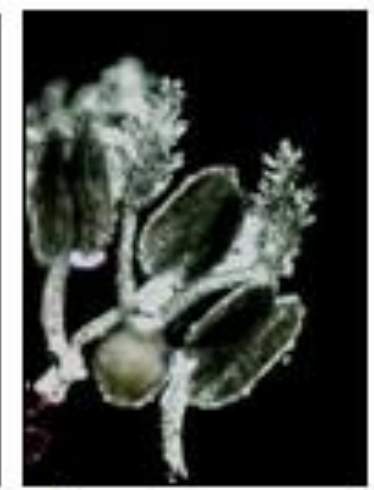

b

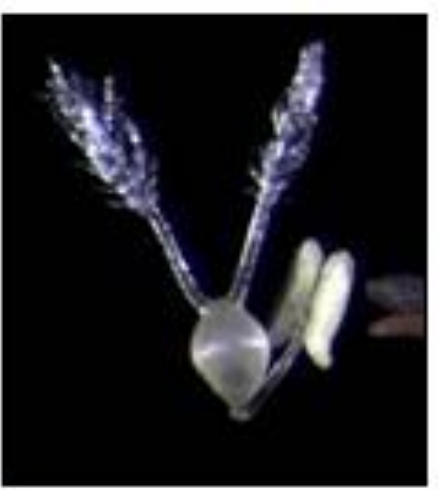

C

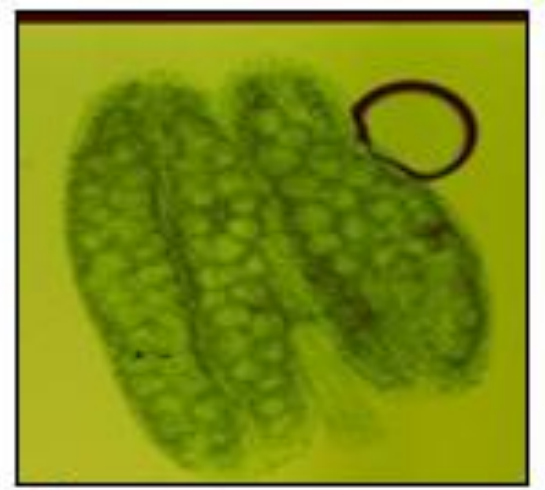

d

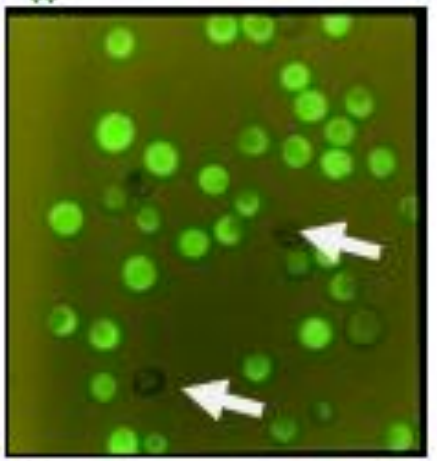

e.

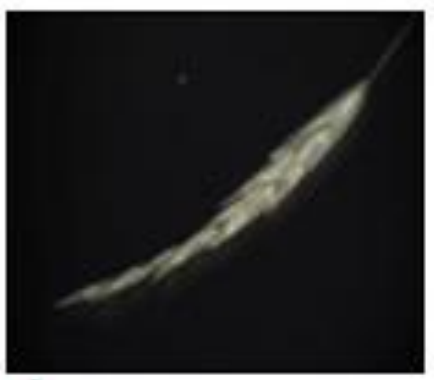

i

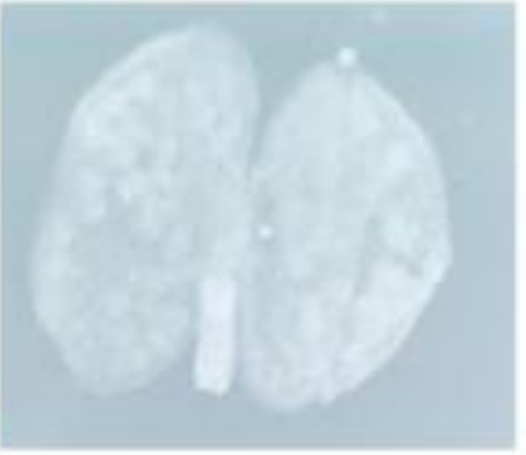

f

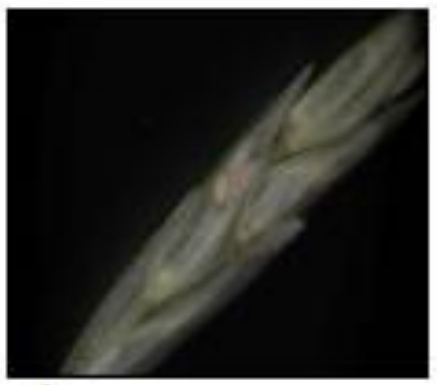

j

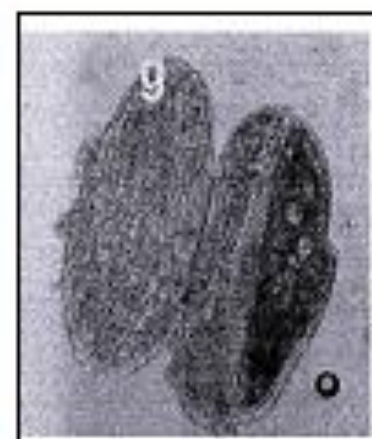

g

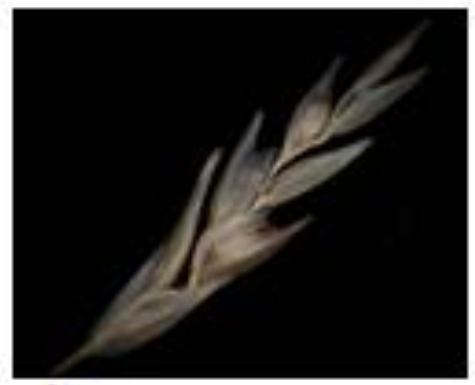

k

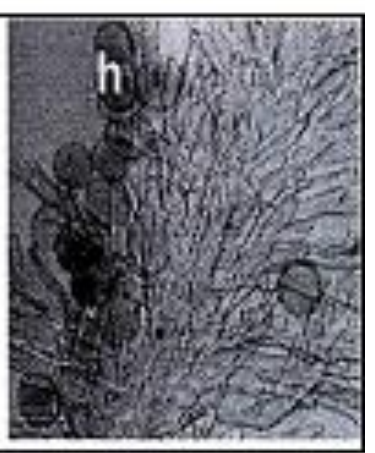

h

Figure 2. Microscopic examination of the R0 lines for male sterility mutants: a) normal pistils and anthers growth of the control plant at anthesis stage compared to the smallest size of di-haploids (b) and the vigor octoploid (c) with variant color (whitish) indicating male sterile anther and herkogamous, incompatibility (physical barrier; short filament of the matured anthers with the fully receptive stigmas d) fertile anther of the control plant, filled with pollen grains e) viable normal fertile pollen grains isolated from matured anthers, larger green (fertile) and smaller and darker (arrows, none fertile) f) deformed pollen grains of the di-haploid anther $\mathbf{g}$ ) shriveled anther of the mutant line with few or no pollen grains $\mathbf{h}$ ) pollinated stigma with un functional pollen grains unable to germinate on the receptive stigma i) fully sterile matured spikelet of the di-haploid j) fully sterile, matured, spikelet of the mutant tetraploid $\mathrm{DH} \mathbf{k}$ ) partially fertile tetaploids $\mathrm{R} 0$.

this culture protocol.

In most cultivars of tef characterized by Ebba (1975), panicles were erect and the occurrence of panicle bending has never been reported. However, in this study both the octoploid and di-haploid plants showed panicle bending at about 45 to $90 \%$ angles. This new character of bending observed in R0s, if inherited to the next successive generations, it could be a useful trait in the development of lodging resistance varieties, since the center of gravity of the plants will be reduced. Cheverton et al. (1992) and Ketema (1983) suggested that plants with low center of gravity may impart lodging resistant in tef due to inflorescence-culm weight balance.

The gametoclonal variations indicated in this study could increase the diversity of the crop which intern will facilitate the tef breeding program. Especially, if gynogenic tetraploid lines produced from the octoploid parent $(8 n)$ would lead to the production of haploids in 
this case tetraploid plants (with bigger seed sizes to increase the quality of the crop and also reduce lodging coping with deeper rooting capacity and stiffer culm which may intern be suited to mechanized farming.

It is well established that male sterility is the useful tool for crop improvement in the development of hybrids and production of hybrid seeds, in facilitating population improvement, backcrossing, interspecific hybridization and other related breeding producer. This valuable character occurs spontaneously in nature but it can also be induced by mutagenesis and tissue culture derived somaclonal and gametoclonal variants. According to the study of Cai et al. (1983), male sterile mulberry plant was obtained from mutagenesis. The existence of male sterility mutants in this study is in agreement with the study of Elkonin et al. (1994). They reported male sterile sorghum lines from cultures of leaf explants taken from haploid plants. They recognized male sterile plants with the production of anthers without pollen grains dehisced on fresh receptive stigmas. Besides, production of 0 to 1 seed per spikelet was considered as completely sterile mutant, which is in agreement with the present report. Achievement of male sterility mutant lines and utilization of the gametoclonal variants in the breeding program may facilitate the improvement of the crop and release of new cultivars in a shorter period compared to the conventional approach.

\section{REFERENCES}

Ayele M, Dolzel J, Duren MV, Brunner H, Zapata-Arias FJ (1996). Flow cytometric analysis of nuclear genome of the Ethiopian cereal Tef (Eragrostis tef (zucc.) Trotter. Genetica 98:211-213.

Bairu MW, Aremu AO, Van Staden J (2011). Somaclonal variation in plants: causes and detection methods. Plant Growth Regul. 63:147173.

Berhe T (1976). A Breakthrough in t'ef breeding technique. FAO inf. Bull. Cereal Imp. and Prod. Near East Project 12(3):11-13.

Bhowmik P, Dirpaul J, Polowick P, Ferrie A (2011). A high throughput Brassica napus microspore culture system: influence of percoll gradient separation and bud selection on embryogenesis. Plant Cell Tissue Organ Cult. 106(2):359-362.

Cai DT, Chen DT, Zhu H, Jin Y (1983). In vitro production of haploid plantlets from the unfertilized ovaries and anthers of Hubei Photosynthetic Male Sterile Rice (HPGMR0, Acta Biol, Exp. Sin. $21: 401-407$

Central Statistical Authority (2008). Agricultural sample survey, 2007/08, Volume IV. Report on land utilization (private peasant holdings, meher season). Statistical Bulletin. 302, Addis Ababa, Ethiopia.

Cheverton M, Pullen M, Didehvar F, Jones G (1992). Database of accessions in the Eragrostis tef Germplasm Collection at Wye. In interim Report, Tef Improvement Project. Wye College, Uni. London.
Ebba T (1975). Tef (Eragrostis tef) cultivars morphology and classification. Part II. Agricultural Experiments Station Bulletin, 66, Addis Ababa University, College of Agriculture, Dire Dawa, Ethiopia.

Elkonin LA, Gudova TN, Ishin AG (1994). Inheritance of male sterility mutations in haploid sorghum tissue culture. Euphytica 80:111-118.

Evans DA, Sharp WR (1985). Somaclonal and gametoclonal variation. In: Handbook of plant cell culture: Techniques and application, Vol. 4. (Evans DA., Sharp WR., Ammirato PV. Macnolla. (eds). New York: pp. $97-132$.

Gugsa L, Sarial AK, Lörz H, Kumlehn J (2006). Gynogenic plant regeneration from unpollinated flower explants of Eragrostis tef (Zuccagni ) Trotter. Plant Cell Rep. 51:287-1295.

Hoekstra S, Vanzijderveld MH, Heidekamp F, Vandermark F (1993). Microspore culture of Hordeum vulgare L. The influence of density and osmolality. Plant Cell Rep. 12:661-665.

Hoffmann F, Thomas E, Wenzel G (1982). Anther culture as a breeding tool in repa. Theor. Appl. Genet. 61:225-232.

Huang B (1996). Gametoclonal variation in crop improvement, In In vitro haploid production in higher plants. (eds) SM Jain, SK Sopory, RE Veilleut, 2:75-81.

lijima K, Sanada A, Iwai R, Toyohara H, Komamine A, Fujimaki H (2010). Ploidy-variations appearing in tissue culture of water yam (Dioscorea alata L.). AsPac J. Mol. Biol. Biotechnol. 18(1):155-157.

Jazdzewska E, Sadoch Z, Niklas A, Majewska-Sawka (2000). Plant regeneration from sugar beet leaf protoplasts: Analysis of shoots by DNA fingerprinting and restriction fragment length polymorphism. Can. J. Bot. 78(1):10-18.

Kahrizi D, Mohammadi R (2009). Study of androgenesis and spontaneous chromosome doubling in barley (Hordeum vulgare L.) genotypes using isolated microspore culture. (Hordeum vulgare L.) genotypes using isolated microspore culture. Acta Agronomica Hungarica 57(2):155-164.

Kanda M, Kikuchi S, Takaiwa F, Oono K (1988). Regeneration of variant plants from rice (Oryza sativa L.) protoplasts derived from long term cultures. Jpn. J. Genet. 63:127-136.

Ketema S (1983). Studies of lodging, Floral Biology and Breeding Technique in tef (Eragrostis tef (zucc.) Trotter). PhD Thesis University of London, Royal Holloway College Eghum, UK. pp. 122.

Khush GS, Virmani SS (1996). Haploids in plant breeding In: In vitro Haploid Production in Higher Plants (S.M. Jain, S.K. Sopory, R.E. Veilleux, editors), Kluwer Academic Phillips. pp 11-33.

Kumlehn J, Serazetdinova L, Hensel G, Becker D, Lörz H (2006). Genetic transformation of barley (Hordeum vulgare L.) via infection of androgenetic pollen cultures with Agrobacterium tumefaciens. Plant Biotechnol. J. 4:251-261.

Malik AA, Cui L, Zhang S, Chen Jin-feng (2011). Efficiency of SSR markers for determining the origin of melon plantlets derived through unfertilized ovary culture. Hortic. Sci. (Prague). 38(1):27-34.

Murashige T, Skoog F (1962). A revised medium for growth and bioassay with tobacco tissue cultures. Physiol. Plant 15:473-497.

Picard E, Buyser J (1977). High production of embryoids in anther culture of pollen derived homozygous spring wheat. Ann. Amelior. Plant (24): 483-488

Singh BD (1986). Polyploidy in plant breeding. In Plant Breeding: Principles and methods. Kalyani Publishers, Ludhiana, New DelhiNoida. pp. 451-484. 